\title{
Interfacial Studies of Double Carbonate Thermionic Oxide Cathodes over Accelerated Operational Life
}

\author{
Daniel Barber ${ }^{a}$, Stephen Jenkins ${ }^{\text {b* }}$, Mark Whiting ${ }^{a}$, Mark Baker ${ }^{\mathrm{a}}$ \\ ${ }^{a}$ School of Engineering, University of Surrey, Guildford, United Kingdom b LG.Philips-Displays, \\ ${ }^{b}$ lackburn, United Kingdom *Philips Road, Blackburn, BB1 5RZ, United Kingdom Telephone number: \\ $++44(0) 1254-507377$ Email:Stephen.Jenkins@lgphilips-displays.com Fax number: $++44(0) 1254-507402$
}

\section{Introduction}

At the last International Vacuum Electron Sources Conference, held in Saratov, Russia, the current authors presented a paper reporting on preliminary findings from an investigation into the interfacial layer that forms in the oxide cathode over accelerated cathode life (Jenkins et al. 2003). It was reported that studies were being conducted to investigate key issues that could bring about improvement in performance to the oxide cathode, in order for the oxide cathode to remain a competitive display technology. One of the key issues identified was the need for characterisation of the interface layer that forms during the operation of an oxide cathode. Although this subject has been investigated extensively before (Rooksby 1940) (Rooksby 1947) (Eisenstein 1949) (Wright 1947), ambiguity remains concerning both the nature and the effect of the interfacial layer on the performance of the oxide cathode. There is firm evidence to indicate that this interfacial layer blocks the 'activating' elements which are necessary for the reduction of the barium oxide in the emissive layer to give the free barium that lowers the work function. This blocking effect, therefore, reduces the performance of the cathode. In this study the interfacial layer was characterised using a number of analytical techniques in order to obtain a comprehensive understanding of the geometry and chemistry of this layer. The techniques that have been used are scanning electron microscopy (SEM), Auger electron spectroscopy (AES), secondary ion mass spectroscopy (SIMS) and transmission electron microscopy (TEM).

\section{Experimental}

Dummy tube electron gun assemblies were constructed and operated under simulated accelerated lifetime testing for $0 \mathrm{~h}, 1000 \mathrm{~h}$ and $2000 \mathrm{~h}$. A range of sample preparation methods was used during this study for emissive oxide layer removal. The first entailed stripping the oxide coating away from the nickel substrate with tape (sometimes repetitively) until the oxide coating was removed from a sizeable amount of the cathode area, thus exposing the underlying interface between the nickel and oxide coating. Another method was cross sectioning at the interface. This was achieved in two different ways. The first was producing a tapered cross section by mounting the cathode onto a $10^{\circ}$ aluminium wedge, setting in resin and polishing to a $3 \mu \mathrm{m}$ finish followed by a final polish with a silica oxide particle suspension. The final type of cross sections were obtained by initially stripping the coating, followed by etching away material from both sides of an area of interest with a focused ion beam (FIB). Specimens were investigated with TEM. SEM/EDX images and spectra were acquired at $15 \mathrm{keV}$ on a Jeol 8600 Super probe using an Oxford Instruments INCA EDX detector. AES spectra were collected using a VG Microlab Mk II, using a York field emission gun set at $15 \mathrm{keV}$ with a specimen current of $12 \mathrm{nA}$. The spherical analyser was operated at CRR 4. A liquid gallium source was used when etching with the FIB. It was operated with a beam energy of $30 \mathrm{keV}$ and $12 \mathrm{nA}$. SIMS depth profiles and images were collected using pulsed $25 \mathrm{keV}$ gold ions $(0.03 \mathrm{pA})$ for the analysis and $1 \mathrm{keV}$ oxygen ions were used to etch into the sample bulk during profiling. TEM images, electron diffraction patterns and EDX spectra were obtained using a Philips CM200 TEM operating at $200 \mathrm{keV}$.

\section{Results}

Past AES and SEM spectra indicated the presence of a skin-like layer consisting of $\mathrm{Ba}, \mathrm{Sr}, \mathrm{Al}$ and $\mathrm{O}$ on the surface of the nickel. Large cracks were also present at the nickel grain boundaries. These cracks developed and continued to grow both in length and width during the lifetime of the cathode. It has been shown that the $\mathrm{Mg}$ activator was located within these large cracks (Barber et al. 2004). More recently, top-down SIMS images of the surface after stripping of the emissive layer

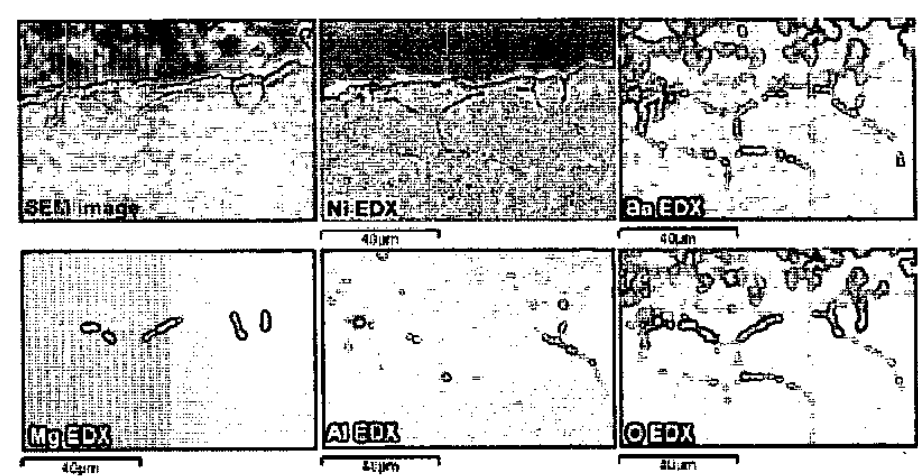

Figure 1. SEM image and EDX maps from a tapered cross section of a cathode with an accelerated operational time of $2000 \mathrm{hrs}$.

0-7803-8437-7/04/\$20.00 @2004 IEEE.

-108 - 
highlighted the presence of $\mathrm{Mg}$ at mouth of the cracks. SIMS depth profiles were acquired from the whole of the SIMS mapping area. The depth profile from a crack region showed that the $\mathrm{Mg}$ signal was constant throughout the depth of the crack. A 3D model confirmed that throughout the profiled volume, $\mathrm{Mg}$ was localised at the crack regions. A depth profile of the skin region away from any cracks was acquired as well. Here there was no Ni signal for the first 20 seconds of the depth profile, but there were high intensities of $\mathrm{Al}, \mathrm{Sr}$ and $\mathrm{Ba}$ present, consistent with the hypothesis of the thin skin.

Tapered cross sections were produced for cathodes that were activated but not aged. In addition, they were made with cathodes that were activated and aged $(0 \mathrm{~h}$ lifetime), had an accelerated $1000 \mathrm{~h}$ lifetime and $2000 \mathrm{~h}$ lifetime. In the first instance, when the cathode was activated but not aged, it was observed that interactions at the interface had taken place. From EDX maps of these samples there was evidence for the presence of this skin and internal oxidation of the nickel. Cross sections of cathodes that were activated and aged showed the initial development of cracks. EDX maps of these areas highlighted very intense $\mathrm{Mg}$ signals from these regions. All of the aforementioned observations were

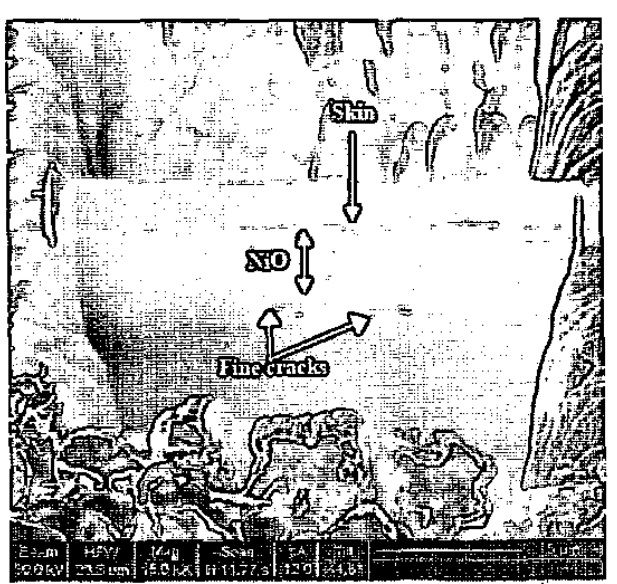

Figure 2. Ion image of the FIB cross section for TEM of a cathode operated for 2000 hours accelerated life.

more common with increased operation time, to the point where SEM and EDX analysis showed that these cracks formed a network, which could underpin the nickel grains as shown in figure 1 . Cross sections were produced with FIB for cathodes that were operated for $0 \mathrm{hr}, 1000 \mathrm{hr}$ and $2000 \mathrm{hr}$ of accelerated life (see figure 2). In all the images a very complex structure of layers were present. It seemed that there was a thin layer (skin) beneath which was nickel oxide; believed to form by internal oxidation of the nickel during the operation of the cathode. It was clearly seen that the $\mathrm{NiO}$ layer thickness increased as a function of time. Finally at the $\mathrm{NiO}$ layer / bulk nickel interface fine cracks were readily found. Within these horizontal fine cracks it was possible to find $\mathrm{Ba}, \mathrm{Sr}, \mathrm{Al}, \mathrm{O}$ and $\mathrm{Mg}$. Although the fine cracks $(5 \mu \mathrm{m})$ were oxidised in nature, $\mathrm{Al}, \mathrm{Ba}$ and $\mathrm{Sr}$ were associated together but $\mathrm{Mg}$ was a separate precipitate.

\section{Conclusions}

A range of surface and analytical techniques were used to investigate the interactions taking place at the oxide cathode interface during operation. Large cracks were found to form in the bulk alloy, these regions being rich in $\mathrm{Ba}, \mathrm{Mg}, \mathrm{Al}$ and $\mathrm{O}$. It seemed probable that internal oxidation of the nickel was taking place and these cracks form an internal surface at which the barium oxide was being reduced by the $\mathrm{Mg}$ and $\mathrm{Al}$ activators. In addition, a thin layer reaction product containing $\mathrm{Ba}, \mathrm{Sr}, \mathrm{O}$ and $\mathrm{Al}$ formed at the nickel alloy / nickel oxide interface. There was a direct correlation between the thickness of the interfacial nickel oxide and operational time. The observations support the view that the majority of cracks formed during activation and ageing. Whilst these cracks continued to grow during accelerated lifetime testing, the number of cracks

Rem ained constant. The fact that the skin layer only contained the $\mathrm{Al}$ activator and the cracks contain both $\mathrm{Mg}$ and $\mathrm{Al}$ activators, coupled with the higher $\mathrm{Mg}$ diffusion coefficient suggested $\mathrm{Al}$ was particularly associated with cathode life performance with $\mathrm{Mg}$ being most important in the earliest stages of cathode operation.

\section{Acknowledgements}

We would like to thank Mr. Peter Heard from Bristol University for his work on the FIB as well as Dr. Vlad Stolojan for his contribution with the TEM. We would also like to thank ION-TOF, Gmbh, Munster, Germany, for the use of the SIMS instrument and Dr Marie-Laure Abel for her help with the interpretation of results. A special thanks to the ESPRC and the CASE sponsor LG.Philips-Displays for the funding of this research project.

\section{References}

[1] Jenkins, S.N., Barber, D. K., Whiting, M. J., Baker, M. A. (2003) Applied Surface Science, 215, 78.

[2] Rooksby, H. P. (1940) J. Roy. Soc. Arts. 88, 308. Rooksby, H. P. (1947) Nature, 159, 609. [3]Eisenstein, A. (1949) J. Appl. Phy. 22, 2,776

[3] Wright, D. A. (1947) Proc. Roy. Soc. Lond. 190,394

[4] Barber, D. K., Jenkins, S. N., Whiting, M. J.,Baker, M. A. (2004) Submitted to Surface Interface Analysis, accepted for print, Wiley. 